\title{
REGULARIZAÇÃO FUNDIÁRIA E COMUNIDADES REMANESCENTES DE QUILOMBO: A CRIAÇÃO DE TERRAS QUILOMBOLAS EM ÁREAS PERIURBANAS
}

\author{
LAND REGULARIZATION AND THE QUILOMBO REMAINING \\ COMMUNITIES: THE CREATION OF QUILOMBO LANDS IN THE PERIURBAN \\ AREAS
}

\author{
${ }^{1}$ Luana Nunes Bandeira Alves \\ ${ }^{2}$ Girolamo Domenico Treccani
}

\section{RESUMO}

Este trabalho analisa a temática referente à regularização fundiária de comunidades remanescentes de quilombo, a partir da possibilidade do reconhecimento destas terras em áreas periurbanas, tendo por objetivo fomentar a discussão acerca dos desafios enfrentados por estes sujeitos em relação à regularidade de seus territórios. A análise parte de uma exposição teórico-normativa envolvendo a questão da delimitação das áreas perirubanas e do reconhecimento de territórios quilombolas. Contudo, ao final, é realizado um estudo de caso para verificar quais as particularidades podem ser constatadas dentre as problemáticas vivenciadas no Quilombo do Abatacal-PA, localizado na região metropolitana de Belém.

Palavras-chave: Regularização fundiária, Áreas periurbanas, Comunidades remanescentes de quilombo, Quilombo do abacatal, Políticas públicas

\begin{abstract}
This paper analyzes the thematic regarding land regularization of quilombola communities, from the problematic possibility of quilombola land recognition in the peri-urban areas with the objective to foment the discussion about the challenges of this communities related with the regularization of this territories. In this sense, the analysis shows a theoretical and rules involving the question of delimitation of peri-urban areas and the recognition of quilombola territories for. However, in the end, is realized a case study and verify the particularities could be observed in the problematics experienced of Quilombo do Abacatal-PA, located in the metropolitan region of Belém.
\end{abstract}

Keywords: Land recognition, Peri-urban areas, Quilombo comunities, Quilombo of abacatal, Public politics

\footnotetext{
1 Mestranda em Direito, com ênfase em Direitos Humanos e Meio Ambiente, pela Universidade Federal do Pará. Advogada. Universidade Federal do Pará - UFPA, Belém, Pará. Brasil

E-mail: Iuanabandeiraalves@gmail.com

2 Doutor em Desenvolvimento Sustentável do Trópico Úmido pelo Núcleo de Altos Estudos

Amazônicos. Advogado. Núcleo de Altos Estudos Amazônicos - NAEA, Belém, Pará. Brasil

E-mail: jeronimotreccani@gmail.com
} 


\section{INTRODUÇÃO}

O direito territorial que assegura a propriedade coletiva às comunidades quilombolas se encontra previsto: no art. 68 do Ato das Disposições Constitucionais Transitórias (ADCT), o qual carrega o status de norma constitucional; na legislação infraconstitucional, a exemplo do Decreto $n^{\circ}$. 4.887, de 20 de novembro de 2003 que trata da regulamentação do processo de regularização das terras quilombolas; bem como pelo art. 332 da Constituição do estado do Pará.

Nesse sentido, é garantido formalmente o acesso às terras ocupadas pelas comunidades remanescentes de quilombo, ocorre que este processo está inserido em questões referentes ao ordenamento territorial e ao uso do solo, uma vez que, em decorrência do espraiamento das cidades e da urbanização sem planejamento, diversos problemas têm sido enfrentados por esses grupos etnicamente diferenciados, principalmente, nas chamadas áreas perirubanas, as quais representam os espaços em que há a coexistência de características rurais e urbanas.

Assim, busca-se discutir os desafios enfrentados pelas referidas comunidades e a regularização fundiária destes territórios localizados em áreas consideradas periurbanas. Nesse sentido, a análise da problemática será realizada a partir de um levantamento bibliográfico e normativo para, posteriormente, adentrar na perspectiva do estudo de caso acerca da Comunidade Quilombola do Abacatal, localizada no município de Ananindeua, região metropolitana de Belém.

Inicialmente, é apresentada a atual discussão acerca do ordenamento territorial e a construção a respeito do conceito de áreas periurbanas, uma vez que o desenvolvimento territorial realizado no Brasil tem levado a uma contínua descentralização espacial, bem como redefinido a ideia de contraposição entre o urbano e o rural, destacando-se a perirubanização, a qual resulta de um processo de urbanização difuso que estende para novos espaços tanto os benefícios quanto as problemáticas próprias da vida urbana.

Em um segundo momento é relacionada a questão da regularização fundiária de comunidades remanescentes de quilombo de forma geral para, em seguida, tratar especificamente da possibilidade de reconhecimento de terras quilombolas nas áreas não consideradas estritamente rurais, com fundamento no art. 68 do ADCT e da legislação infraconstitucional. 
Após esses dois primeiros momentos com enfoque primordialmente teóriconormativo, é realizado um estudo de caso acerca dos problemas enfrentados pela Comunidade Quilombola do Abacatal, a qual se encontra localizada no município de Ananindeua, estado do Pará; e, embora esteja incluída em uma área considerada urbana pelo plano diretor municipal, em virtude do espraiamento das cidades, atualmente, vivencia as consequências decorrentes da urbanização sem planejamento, como, por exemplo, o despejo de esgoto sanitário em seus igarapés por conta dos condomínios fechados situados no entorno desta localidade.

Por fim, é com base nos desafios apresentados pela dinamicidade destes espaços que é proposta a discussão acerca das dificuldades enfrentadas especificamente pelas comunidades quilombolas em relação à efetivação da regularização fundiária de seus territórios.

\section{ORDENAMENTO TERRITORIAL E DELIMITAÇÃO DAS ÁREAS PERIURBANAS}

O desenvolvimento territorial realizado no Brasil tem levado a uma contínua descentralização, bem como redefinido a ideia de contraposição entre o urbano e o rural. Nesse sentido, se faz necessária a releitura do ordenamento territorial nesses diferentes espaços considerados pela geografia enquanto instrumentos para compreender as dificuldades e impossibilidades de pensar o planejamento de diferentes territórios na atualidade, destacando a aplicabilidade do sistema jurídico, através de políticas públicas adequadas, na efetivação de direitos e garantias fundamentais, assim, Dias (2014, p. 11) destaca que:

A reflexão sobre o papel do Estado e do planejamento para o controle do espaço-
seus limites e desafios - é encetada por meio da reflexão sobre o papel do Estado no
controle do espaço e os desafios para o planejamento e ordenação dos territórios,
considerando os novos significados para o espaço o tempo. A reflexão crítica sobre
a finalidade do planejamento, na atualidade, tem por meta possibilitar a organização
do espaço e a inserção de camadas populacionais segregadas histórica, cultural,
econômica e territorialmente. Sem esses objetivos, nenhum estudo crítico sobre a
realidade, jurídica e social, seriam factíveis.

A respeito dessa discussão, Endlich (2006) coloca que existem diferentes critérios de definição sobre a configuração dos espaços urbanos e rurais a serem analisados complementarmente, são eles: limites oficiais ou delimitação administrativa, delimitação de um patamar demográfico, densidade demográfica e ocupação econômica da população. 
A delimitação administrativa remete à ideia de rural e urbano como adjetivos espaciais, pois se fundamenta nos limites estabelecidos oficialmente pelo Estado, sendo esta a concepção adotada pelo Brasil.

De acordo com Fischer (2014), a definição do perímetro urbano é uma das competências municipais a partir da qual o município delimita o seu espaço para o exercício do poder de polícia de controle do parcelamento e uso do solo, sendo que para essa definição é utilizado o critério jurídico, segundo as disposições do art. $3^{\circ}$ do Decreto-Lei no n $^{\circ} 311$, de 2 de março de 1938.

Ainda a respeito do critério administrativo, é interessante notar que, segundo Veiga (2004), em outros países é comum a combinação entre critérios estruturais, como: número de habitantes ou densidade; e funcionais, a exemplo dos serviços indispensáveis aos citadinos, sendo que o Brasil se distingue mundialmente por considerar como cidades locais tão precários, nos quais não há sequer escolas ou transporte coletivo.

Nesse contexto, de acordo com Endlich (2006), as definições de caráter demográfico remetem à ideia de um rural como dispersão e o urbano enquanto aglomeração, porém essa concepção mostra-se insuficiente para avaliar questões importantes, como, por exemplo: a riqueza ou a pobreza; e o nível de educação dos habitantes.

No que tange à vinculação em razão da ocupação econômica, atualmente, esta se encontra superada, já que se fortalece o posicionamento de que diversas atividades vêm sendo desenvolvidas no campo, o que constitui o novo rural. Sendo assim, Veiga (2007) destaca que nos territórios rurais mais dinâmicos predominam as atividades terciárias, principalmente serviços que geram fluxo de capital, a exemplo do turismo.

Nesse sentido, o país tem passado por várias modificações socioeconômicas e, em virtude dessas mudanças, pode-se afirmar que os critérios analisados se mostram insuficientes para contemplar as complexidades entre urbano e rural, conforme assinala Endlich (2006, p. 18):

\footnotetext{
Os critérios apresentados propõem considerar o urbano como território políticoadministrativo; aglomerado de pessoas; núcleos com determinada densidade populacional e com população ocupada predominantemente com atividades secundárias e terciárias. Nenhum desses critérios parece corresponder à atual realidade urbana e rural.
}

Sendo assim, a concepção de centralidade é aquela que se mostra mais adequada a esse novo contexto, pois não pressupõe limites fixos entre diferentes espaços. Além disso, a partir dessa visão podem existir várias atividades em uma mesma área. 
O critério da centralidade remete, então, a uma circunscrição administrativa com um aglomerado populacional, condicionada à existência de um polo que influencie as áreas periféricas, portanto, a ideia do urbano pode se estender para além das cidades, se relacionando diretamente com o rural e, consequentemente, superando a ideia de compartimentação entre essas áreas.

Dessa forma, com o espraiamento das cidades, Davis (2006) destaca que o processo de urbanização deve ser conceituado enquanto uma interação de todos os pontos como um contínuo urbano-rural, uma vez que, em diversos casos, a população rural não necessita migrar para as cidades, pois as próprias cidades se estendem aos demais espaços no atual contexto, a esse exemplo destacamos o conceito de "novo rural".

Assim, se fortalece a necessidade da consolidação de ideias ainda em construção como a questão das áreas periurbanas e da periurbanização, as quais resultam do processo de urbanização difusa que estende para variados locais tanto os benefícios quanto as problemáticas próprias da vida urbana.

Embora haja um fortalecimento dessa discussão, há autores, como Saquet (2013) que se posicionam contrários ao desenvolvimento de novas concepções para tratar desses arranjos territoriais em que o rural e o urbano se misturam. Nessa perspectiva, o referido autor afirma não ser necessário inventar palavras a exemplo de rururbano para as problemáticas atuais, sendo, então, fundamental mostrar e explicar as relações sem eliminar as peculiaridades de cada espaço. No entanto, a importância dessa discussão é refletida diretamente no desenvolvimento de políticas públicas, especialmente aquelas voltadas ao ordenamento territorial, em espaços nos quais se verifica uma textura onde coexistem características urbanas e rurais sem que haja o predomínio de um sobre o outro.

Segundo Vale e Gerardi (2006), a discussão da periurbanização possui um sentido amplo, uma vez que trata das áreas nas quais ocorre um crescimento periférico e onde os usos urbanos e agrários se misturam, configurando uma zona de transição entre a cidade e o campo.

Por se tratar de um conceito aberto, ainda em construção, diversas podem ser as suas implicações, dentre as quais destacamos a relação entre o processo de periurbanização com o uso do solo e as questões voltadas à implementação de infraestrutura nesses espaços. Assim, ressaltamos que: 


\begin{abstract}
agrícolas em terrenos urbanos ou a implantação de indústrias em áreas rurais. A questão é que, no espaço periurbano, a intensificação dessa mistura é tamanha que dificulta a separação entre rural (ou agrícola) e urbano. Isso implica que a dinâmica periurbana tenha características próprias, daí consideramos a importância do periurbano muito mais pela sua dinamicidade do que pelo fato de ser um espaço rural ou urbano. (VALE; GERARDI, 2006)
\end{abstract}

Contudo, é enfocando nos desafios apresentados pela dinamicidade das áreas periurbanas que serão discutidas as dificuldades enfrentadas por comunidades remanescentes de quilombo em virtude da necessidade de efetivação da regularização desses territórios etnicamente diferenciados.

\title{
3 REGULARIZAÇÃo FUNDIÁRIA DE QUILOMBOS EM ÁREAS PERIURBANAS
}

$\mathrm{O}$ reconhecimento e a regularidade fundiária de quilombos se tornam um desafio particular para as políticas de ordenamento territorial na Amazônia em razão da histórica ocupação do solo urbano e rural que, originalmente pertencia ao Estado e, gradualmente, foi sendo apropriado por agentes privados.

Segundo Fischer (2014), há casos de municípios, no Estado do Pará, como por exemplo: Bannach, que litigam com particulares a respeito da titularidade das terras de seu núcleo urbano, sendo importante, então, a realização do processo de discriminação a fim de identificar a legítima titularidade destas terras para, posteriormente, regularizá-las de acordo com o instrumento jurídico mais adequado.

Nesse sentido, Rocha et al. (2015) esclarece que o procedimento discriminatório tem por finalidade identificar e separar as terras públicas das particulares, sendo que o seu fundamento jurídico está assentado no domínio eminente do Estado sobre todos os bens que estão situados no território nacional.

No caso de serem declaradas terras devolutas, estas deverão ser incorporadas ao patrimônio público, assim é importante destacar que, no tocante aos bens públicos, estes poderão ser pertencentes à União, aos Estados e aos Municípios ${ }^{1}$.

Dessa forma, quanto aos bens da União, estes se encontram previstos no art. 20 da Constituição da República Federativa do Brasil de 1988 (CRFB/1988), sendo pertinente ressaltar que neste rol encontra-se previsto como bem pertencente ao patrimônio público as terras tradicionalmente ocupadas pelos indígenas, definidas pelo art. $231, \S 1^{\circ}$, também do texto constitucional, como aquelas que forem habitadas por estes povos em caráter 
permanente, utilizadas para as suas atividades produtivas, imprescindíveis à preservação dos recursos ambientais e necessárias à sua reprodução física e cultural.

Embora os indígenas tenham seu direito à terra constitucionalmente assegurado, é importante destacar que, diferentemente das comunidades remanescentes de quilombo, os índios não têm reconhecido o direito à propriedade, obtendo somente o usufruto destas terras, conforme ressalta Dezen Junior (2012).

Além disso, de acordo com Prioste et al. (2011) as terras quilombolas não poderão ser vendidas, doadas, penhoradas, arrendadas ou adquiridas por usucapião, conforme previsão expressa da legis lação vigente.

Segundo Anjos (1999), atualmente, o conceito de quilombo tem sofrido ressignificações inclusive em razão do contexto territorial, a partir do qual as cidades se espraiam para outros locais, gerando áreas de transição como os espaços periurbanos. Dessa forma, de acordo com o referido autor, entende-se por remanescentes de quilombo aquelas comunidades descendentes de negros escravizados que vivem nos espaços urbanos, periurbanos e rurais do território brasileiro.

\footnotetext{
${ }^{1}$ No caso específico do patrimônio municipal, Fischer (2014) destaca que este somente poderá ser constituído se inicialmente for realizada doação por parte da União ou de algum estado, sendo que, no aspecto patrimonial, o município dependeria de outros entes federados na fase inicial, justamente para instalação de sua sede, sendo que posteriormente a própria urbanização e a periurbanização se constituiriam enquanto processos facilitadores na aquisição de novas áreas patrimoniais.
} 
Assim, no que diz respeito à regularização de terras quilombolas, esta tem como fundamento jurídico o direito de propriedade que guarda determinadas especificidades, como o fato de ser coletiva, sendo este direito assegurado no art. 68 do ADCT e, no âmbito do estado do Pará, no art. 332 da Constituição Estadual; e considerado enquanto fundamental, tal qual os direitos à propriedade, previsto no art. $5^{\circ}$, inciso XXII; e à moradia, disposto no art. $6^{\circ}$, caput, ambos da CRFB/1988.

Segundo as disposições destas normas, as comunidades quilombolas que estejam ocupando suas terras deverão ter reconhecida a propriedade definitiva, constituindo-se um poder-dever do Estado a emissão dos títulos respectivos.

É legalmente assegurado, assim, o domínio pleno sobre as terras ocupadas pelos negros no âmbito constitucional ${ }^{2}$, sendo isto um marco para o reconhecimento de direitos étnicos, constituindo-se em uma obrigação por parte do Poder Público a titulação dos territórios quilombolas.

Embora ao longo deste trabalho sejam analisadas as problemáticas vivenciadas e os desafios a serem enfrentados pelas comunidades remanescentes de quilombo, inclusive através do estudo de caso da Comunidade do Abacatal, localizada no estado do Pará, Marques e Malcher (2009) afirmam que: este estado foi o primeiro a titular terras quilombolas, o que mais expediu títulos e assegurou o maior volume de hectares aos negros no país.

Com relação à participação destes grupos tradicionais no processo de demarcação e regularização de seus territórios, esta se faz essencial e é assegurada conforme as disposições do art. $8^{\circ}$ do Decreto no 3.572 , de 22 de junho de 1999, do estado do Pará.

\footnotetext{
${ }^{2}$ Segundo Treccani (2006), o fato de o direito territorial das comunidades quilombolas ter sido incluído em uma norma contida no ADCT, esta não pode ser considerada como inferior ou secundária com relação às demais normas constitucionais, uma vez que derivam do mesmo poder constituinte.
} 
Em âmbito federal o procedimento para a identificação, o reconhecimento, a delimitação, a demarcação e a titulação das terras ocupadas pelos quilombolas, é regulamentado pelo Decreto $\mathrm{n}^{\mathrm{o}} 4.887 / 2003^{3}$, segundo o qual a propriedade quilombola diz respeito às terras ocupadas por estas comunidades e utilizadas para a sua sobrevivência e reprodução social, sendo o Instituto Nacional de Colonização e Reforma Agrária (INCRA) responsável pela realização do processo administrativo de titulação em âmbito federal.

Nas hipóteses em que as terras não forem pertencentes à União, mas aos Estados, será, então, atribuída a competência para a titulação de territórios quilombolas a um órgão estadual específico, como é o caso do Instituto de Terras do Pará (ITERPA).

No caso do estado do Pará, por meio do Decreto n ${ }^{\circ} 713$, de 07 de dezembro de 2007, foram criadas diferentes modalidades de assentamento, conforme ressaltam Marques e Malcher (2009), destacando-se o denominado Território Estadual Quilombola (TEQ), previsto no art. 12 do referido decreto, o qual busca a garantia do etnodesenvolvimento das comunidades quilombolas, devendo ser instituído no prazo de 120 dias após a emissão do título de propriedade.

Ademais, em meio às problemáticas apresentadas, a questão territorial se torna um ponto central a ser discutido para o desenvolvimento de políticas públicas voltadas às comunidades remanescentes de quilombo, uma vez que, ao serem impactadas pelas consequências negativas da urbanização sem planejamento, também passam a experimentar a precariedade de outros direitos essenciais, como: saneamento básico e acesso à moradia adequada.

Nesse sentido, Almeida (2011) ressalta que atualmente as terras de uso comum, destinadas às comunidades tradicionais, tais como aquelas referentes à propriedade quilombola, terminam por enfrentar constantes pressões que interferem diretamente no exercício pleno de direitos básicos por esses sujeitos.

\footnotetext{
3 É importante destacar que a referida norma é objeto da ADI n ${ }^{\circ} 3239$-DF a ser julgada pelo Supremo Tribunal Federal, sendo que, segundo Prioste et al. (2011), é interessante para os ruralistas a declaração de inconstitucionalidade deste decreto, uma vez que este grava esses imóveis como bens fora do comércio. Nesse sentido, com o objetivo de dificultar o processo de regularização das terras quilombolas, há aqueles que defendem a inconstitucionalidade do decreto, argumentando que não caberia a regulamentação do direito de propriedade quilombola por meio dessa espécie de norma. Entretanto, para refutar essa tese, pode-se afirmar que, sendo este direito de propriedade fundamental e com aplicabilidade imediata, o exercício do mesmo prescindiria de regulamentação a nível infraconstitucional, bastando o próprio texto da Carta Magna de 1988 para a efetivação da regularização de terras quilombolas seja em áreas rurais, urbanas ou perirubanas.
} 
Assim, em virtude do contexto apresentado, de acordo com Boyer (2014), se torna obsoleto discutir o conceito de quilombo a partir de uma visão exclusivamente rural, relacionada ao passado, sendo que, segundo Teles (2010), já pode ser verificado um crescente número de processos administrativos voltados à regularização de terras quilombolas em áreas não consideradas rurais, as quais compartilham problemáticas semelhantes resultantes do processo de periurbanização.

Nesse contexto, destaca-se o caso paradigmático do Quilombo Família Silva, o qual teve sua titulação concluída em 2009, sendo considerado o primeiro quilombo urbano do Brasil. É interessante destacar que o histórico apresentado no Relatório Técnico de Identificação e Delimitação (RTID) do referido quilombo aponta que essa comunidade inicialmente encontrava-se instalada em uma zona considerada rural pelo município de Porto Alegre, porém, com o passar dos anos e com a expansão dos limites da área urbana, o Quilombo Família Silva terminou por ser inserido no contexto urbano e, consequentemente, se tornou sujeito às problemáticas decorrentes, por exemplo, da construção de condomínios fechados nas proximidades de seu território.

Ainda há casos que são considerados controversos em relação ao processo de reconhecimento da propriedade quilombola, a exemplo do Quilombo de Marambaia em que a comunidade pleiteia o direito ao território localizado sobre as terras da Iha de Marambaia, as quais seriam consideradas bens públicos da União. Neste caso, segundo Teles (2010), o território foi reconhecido enquanto quilombola, uma vez que estaria abrangido pela atual interpretação acerca do conceito de remanescente de quilombo.

Além dessas questões, uma problemática comumente enfrentada pelas comunidades quilombolas durante o processo de reconhecimento do seu direito territorial, tanto em áreas urbanas e quanto periurbanas, diz respeito à demora para conclusão dos processos em andamento, sendo importante destacar que, de acordo com Teles (2010), em 2009, o Ministério Público Federal (MPF), por seu Grupo de Trabalho de Quilombolas e Populações Tradicionais da $6^{\mathrm{a}}$ Câmara de Coordenação e Revisão, instaurou um Inquérito Civil Público 
para investigar a situação das políticas públicas voltadas à titulação das terras de comunidades remanescentes de quilombo.

No referido inquérito, o MPF buscou oficiar diversos órgãos relacionados à regularização de terras quilombolas para catalogar os processos existentes e verificar as razões da demora para conclusão dos procedimentos que visam a efetivação de um direito fundamental.

Contudo, contata-se avanços previstos pela legis lação no sentido de efetivar o direito territorial dos remanescentes de quilombo quanto à sua regularidade fundiária, porém, há casos específicos de comunidades que vivenciam problemas decorrentes da vida urbana em espaços anteriormente considerados rurais, áreas estas que foram englobadas pelo espraiamento das cidades gerando locais nos quais se verifica a presença de características urbanas e rurais, constituindo assim os espaços perirubanos que se configuram enquanto um desafio atual a ser enfrentado pelas políticas que visam a regularização de terras quilombolas.

\section{DESAFIOS ENFRENTADOS PELAS COMUNIDADES REMANESCENTES DE QUILOMBO EM ÁrEAS PERIURBANAS: O CASO DA COMUNIDADE DO ABACATAL - PA}

A organização urbana da cidade de Belém, capital do estado do Pará, tem passado por transformações desde sua fundação até os dias atuais em que a expansão da urbanização se estende para a região metropolitana, impactando outras localidades, como o município de Ananindeua, no qual foi titulada a Comunidade Quilombola do Abacatal.

Segundo Araújo (1998), entre os séculos XVII e XVIII a estrutura territorial da cidade se manteve, incorporando determinadas modificações, como a construção de igrejas e conventos. Ocorre que nos séculos posteriores, XIX e XX, a cidade intensifica a atração de recursos na região amazônica e, assim, passa a abrigar diferentes obras decorrentes do processo de urbanização que se adapta à realidade local, caracterizando-se por ser autoreferente, e não sendo comportado por um único padrão urbanístico predeterminado, conforme ressalta o trecho a seguir:

\footnotetext{
Uma dedução lícita que cabe aqui fazer é a demonstração de que os fundamentos do plano da cidade de Belém, não se encontram numa tipologia-padrão, mas são claramente visíveis dentro do desenho concreto da cidade. Ou seja, a estrutura formal da cidade é antes de tudo auto-referente ao assim ser, remete para uma
} 
atividade de cunho metodológico, para uma valorização do "método" em detrimento do modelo". Outra vez vem à tona à formação dos profissionais do urbanismo e seu quadro de referências formais, que dotam os seus desenhos da capacidade de indicar os códigos de sua própria leitura. (ARAÚJO, p . 229).

As técnicas e os modelos de planejamento na execução de políticas públicas, de acordo com Dias (2014), devem compreender a organização do espaço coletivo para a realização do bem estar de todos, sendo necessário considerar os ambientes rurais, urbanos, periurbanos e as necessidades de seus habitantes.

Em contramão a este pensamento, durante grande parte do histórico de formação da cidade de Belém a questão do território não se desvinculou totalmente de seu desenho consolidado originalmente, ao ponto de surgir a necessidade efetiva de criação da região metropolitana, a qual, de acordo com Corralo (2006), somente é criada em razão da ineficiência da cidade central em disponibilizar a infraestrutura necessária ao atendimento das necessidades básicas dos citadinos.

Nesse sentido, o Quilombo do Abacatal está inserido no contexto em discussão, pois se encontra localizado no município de Ananindeua, região metropolitana de Belém, resultante justamente do espraiamento da urbe para outros espaços.

Historicamente colocando a consolidação deste quilombo, de acordo com Marin e Castro (2004), no século XIX o espaço rural de Belém passava por rápidas transformações, em razão da construção de novas paisagens com um intenso aumento de moradores e seus escravos. Durante esse período ocorreram diversas revoltas que resultaram na organização de quilombos como um instrumento de resistência à ordem imposta aos negros nessa região.

É importante destacar que muitos quilombos foram destruídos por iniciativa do Estado, sendo que dentre aqueles que resistiram está a Comunidade do Abacatal, localizada em Ananindeua, a qual teve sua formação a partir da relação entre o Conde Coma Mello, senhor de escravos, e a escrava Olímpia que resultou no nascimento de três crianças, tendo o Conde deixado suas terras a esses filhos que foram reconhecidos, sendo este o relato dos atuais integrantes do grupo, segundo Marin e Castro (2013).

Em virtude da luta desta comunidade pelo reconhecimento de seus direitos territoriais, no dia 13 de maio de 1999 a Associação dos Moradores e Produtores Quilombolas de AbacatalAurá foi titulada com uma área de 317,9366ha, porém em 2008 a área da propriedade teve um acréscimo de 265,3472ha em sua extensão. Essa alteração foi realizada porque o espaço acrescido estava inicialmente destinado à construção da Alça Viária, no entanto, terminou por não ser 
utilizado, conforme aponta o Plano de Utilização dos Remanescentes de Quilombo do Abacatal instituído pelo Instituto de Terras do Pará para atender às determinações do Decreto-Lei ${ }^{\circ}$ 7.454, de 19 de fevereiro de 1971; e da Instrução Normativa do ITERPA n ${ }^{\circ}$. 03, de 9 de junho de 2010, as quais dispõem acerca dos territórios estaduais quilombolas.

Nesse sentido, por meio da Portaria $\mathrm{n}^{\mathrm{o}} 2.857 / 2010$, o ITERPA criou o Território Estadual Quilombola Abacatal-Aurá, sendo o TEQ homologado pelo Decreto $\mathrm{n}^{\circ} 2.690$, de 28 de dezembro 2010 que, de acordo com os seus considerandos, dispõe que a criação deste território visa promover o etnodesenvolvimento das comunidades remanescentes de quilombo, assegurando a estes cidadãos os seus valores sociais e culturais, bem como a melhoria de sua qualidade de vida.

Embora o Plano de Utilização dos Remanescentes de Quilombo do Abacatal preveja que qualquer intervenção dentro do quilombo por pessoas estranhas à área deva ser precedida de autorização explícita da Associação e estar em conformidade com o referido plano, com a expansão da urbanização surge o sentimento de apreensão entre os moradores da comunidade, sendo forjados vários conflitos e problemáticas que colocam em risco o direito territorial deste grupo, se fazendo importante destacar que essas ameaças são comumente materializadas por meio de: despejos e perseguições.

Dessa forma, de acordo a Secretaria de Justiça e Direitos Humanos do Estado do Pará (2015), atualmente, os problemas ambientais vividos pelos membros da Comunidade do Abacatal, ocorrem em razão dos empreendimentos imobiliários construídos e do aterro sanitário da empresa Revita, ao entorno do território quilombola.

É interessante notar que, embora a comunidade esteja inserida no contexto dos problemas urbanos, intensificados pela intervenção de agentes privados em detrimento de sua territorialidade, a Lei $\mathrm{n}^{\mathrm{o}} 2.380$, de 09 de julho de 2009, a qual institui as macrozonas urbanas no território municipal de Ananindeua e define o seu perímetro urbano, dispõe em seu art. 13 que: "ficam instituídas as macrozonas rurais: macrozona rural das ilhas; e macrozona rural do Abacatal" (ANANINDEUA, 2009, grifo nosso).

É imprescindível ressaltar que a referida lei municipal está em consonância formal com a legislação federal em vigor, qual seja o Decreto $n^{\circ} 311 / 1938$, mas, assim como a norma vigente em âmbito nacional, resta evidente que em nível do município de Ananindeua a delimitação do espaço urbano e rural se fundamenta unicamente no critério político- administrativo que não dá conta das implicações resultantes da perirurbanização. 
Nesse sentido, pode-se afirmar que, embora formalmente este quilombo encontre-se localizado em área rural, em decorrência da expansão da urbanização, este pode ser considerado fundamentalmente como um quilombo periurbano, uma vez que se trata de uma área que congrega características rurais e urbanas.

Assim, ainda a respeito das dificuldades enfrentadas por comunidades quilombolas localizadas em áreas periurbanas, um dos problemas mais graves vivenciados pelo quilombo do Abacatal diz respeito ao aterro sanitário que fica a 200 metros do igarapé Uriboquinha e Aracanga, os quais são essenciais para a reprodução e o modo de vida tradicional daquelas pessoas, sendo assim, ressaltamos que:

\begin{abstract}
Os moradores da comunidade do Abacatal reivindicam o fim do despejo de es goto sanitário por condomínios, situados ao entorno da área, em igarapés e na única via acesso ao território. Os resíduos correm a céu aberto e fazem a escoação para os igarapés Aracanga e Uriboquinha, que são utilizados para lazer e sobrevivência de mais de 300 moradores da comunidade. (Secretaria de Justiça e Direitos Humanos do Estado do Pará, 2015).
\end{abstract}

As implicações ambientais negativas que atingem o igarapé Aracanga resultaram na contaminação da água utilizada para atender às necessidades físicas e manter a atividade de subsistência da comunidade, através da pesca, bem como intensificou a contaminação por doenças pela população local, sendo que, segundo Marin e Sabino (2015), houve um agravamento deste problema no período de chuvas, durante o qual o esgoto fica empossado ao longo da Estrada do Abacatal.

Apesar da realidade de precarização vivenciada por este grupo, a Lei nº 2.237, de 06 de outubro de 2006, a qual institui o Plano Diretor do Município de Ananindeua, é objetiva quanto ao dever do Poder Público em assegurar a proteção e conservação deste território a fim de garantir a qualidade de vida das gerações atuais e futuras, conforme positiva o art. 27.

Nesse sentido, segundo o Ministério Público do Estado do Pará (2015), tem sido realizadas reuniões entre os entes governamentais e a Associação de Moradores e Produtores Quilombolas do Território do Abacatal, com vistas a firmar esforços para cumprir com o pactuado no Termo de Ajuste de Conduta (TAC) promovido pelo MPE, em razão dos impactos socioambientais que afetam diretamente a comunidade quilombola.

Diante da importância da regularização fundiária destas terras e dos desafios resultantes das problemáticas emergentes nos espaços periurbanos, se faz necessário repensar as políticas de reconhecimento da propriedade quilombola, a fim de se desenvolver soluções jurídicas aos problemas que impactam negativamente tais grupos etnicamente diferenciados. 
Assim, destacamos, por exemplo, a proposta de Anjos (1999) pela produção efetiva de registros, principalmente cartográficos, que identifiquem e cataloguem as comunidades remanescentes de quilombo nas diferentes regiões do país, a fim de auxiliar na delimitação dos territórios a serem reconhecidos em âmbito federal e estadual, como é o caso do TEQ instituído adequadamente no estado do Pará; possibilitando inclusive a aplicação de investimentos previstos para essas comunidades, tal como o Programa Brasil Quilombola, criado pelo Governo Federal em 12 de março de 2004, o qual, segundo o INCRA (2016), contempla um conjunto de ações governamentais que envolve diversos órgãos; e da possibilidade de acesso a crédito junto ao Conselho Monetário Nacional pelos grupos quilombolas, no âmbito da Política Nacional da Agricultura Familiar, previsto pela Lei ${ }^{\circ}$. 11.326, de 24 de julho de 2006.

Ademais, no caso específico do Quilombo do Abacatal, em virtude do pacto federativo e da complexidade que envolve esta área, defende-se a implementação das disposições do Plano Diretor Municipal, o qual prevê, em seu art. 27, inciso III, alínea b, a constituição de parcerias entre o Município e a União para a promoção da política de habitação no local.

Por fim, verifica-se que a referida comunidade vivencia problemas semelhantes a outros quilombos que inicialmente se encontravam em áreas rurais, mas com a intensificação da urbanização, atualmente, estão inseridos no contexto urbano, podendo-se afirmar que o quilombo localizado no estado do Pará se enquadra na perspectiva dos desafios resultantes dos espaços periurbanos, os quais congregam a complexa relação de características urbanas e rurais, cabendo ao Poder Público o reconhecimento dessa problemática, a efetivação das políticas públicas já existentes e o necessário desenvolvimento de mecanismos que busquem solucionar as dificuldades no processo de regularização fundiária das terras quilombolas.

\section{CONSIDERAÇÕES FINAIS}

A problemática enfrentada pelas comunidades remanescentes de quilombo em relação à regularização de suas terras está relacionada à outras questões resultantes do desenvolvimento territorial, como a constituição das áreas denominadas periurbanas, as quais remetem a uma contínua descentralização e redefinição da ideia fixa de contraposição entre o urbano e o rural. 
Assim, pode-se afirmar que, diante dos critérios teóricos e daquele adotado pelo Brasil em relação à delimitação de áreas urbanas e rurais, a concepção de centralidade é aquela se mostra mais adequada ao atual contexto, em razão disso, observa-se o fortalecimento acerca da necessidade de discussão de novos conceitos, como ocorre com a ideia de áreas perirubanas e da perirurbanização que resultam do processo de urbanização difusa e expande para novos espaços tanto os benefícios quanto as problemáticas próprias da vida urbana.

O grande avanço dessa discussão diz respeito ao desenvolvimento de políticas públicas, em especial aquelas voltadas ao ordenamento territorial, em áreas nas quais se observa uma textura onde coexistem características urbanas e rurais, a partir disso, destacamos a questão da regularização fundiária de terras quilombolas localizadas em áreas perirubanas.

$\mathrm{Na}$ Amazônia, o reconhecimento e a regularidade fundiária de territórios pertencentes à comunidades quilombolas se torna um desafio particular para as políticas públicas implementadas pelo Estado em virtude da histórica ocupação do solo urbano e rural que, originalmente, pertencia ao Poder Público e gradualmente foi sendo apropriado por agentes privados.

Nesse contexto, em razão da problemática acerca da titularidade destas terras se faz necessária a realização do processo de discriminação para identificar a legítima titularidade dessas áreas e, posteriormente, regularizá-las de acordo com o instrumento jurídico mais adequado.

No caso específico das terras quilombolas, a regularização fundiária se encontra regulamentada a nível federal pelo Decreto $n^{\circ} 4.887 / 2003$, o qual é objeto da ADI $n^{\circ} 3239$ DF, sendo utilizada a argumentação de que esta espécie normativa seria inadequada para regulamentação da referida matéria. Ocorre que, com vistas a refutar tal tese, pode-se afirmar que, sendo este direito de propriedade fundamental e com aplicabilidade imediata, o exercício do mesmo prescindiria de regulamentação a nível infraconstitucional, bastando apenas o texto da Magna Carta de 1988 para a efetivação da regularização das terras de comunidades remanescentes de quilombo.

Nesse contexto, a questão territorial se torna um tema central a ser discutido para o desenvolvimento de políticas públicas voltadas às comunidades quilombolas, as quais têm seus territórios impactados pelas consequências negativas da urbanização sem planejamento e 
também passam a experimentar a precariedade de outros direitos essenciais, como: saneamento básico e moradia adequada.

Ademais, há casos como o do Quilombo Família Silva, titulado como primeiro território quilombola urbano do Brasil, o qual inicialmente se encontrava em uma área rural, porém, com a expansão da urbanização, atualmente, está localizado em um espaço central de Porto Alegre-RS, enfrentando diversos problemas decorrentes, por exemplo, da construção de condomínios fechados nas proximidades de seu território.

Após o estudo de caso realizado acerca da Comunidade do Quilombo do Abacatal, no Pará, pode-se afirmar que esta tem passado por um processo semelhante ao do Quilombo Família Silva, já que, embora esteja identificada como inserida no espaço rural pelo plano diretor municipal, é observado que o referido quilombo enfrenta diversos desafios resultantes da urbanização sem planejamento, a exemplo dos empreendimentos imobiliários construídos e do aterro sanitário no entorno do território quilombola.

Dessa forma, pode-se concluir que, ainda que formalmente a comunidade encontrese pertencente a uma área rural, em decorrência da expansão da urbanização, esta pode ser considerada como um quilombo periurbano.

Dessa forma, é com base nos desafios apresentados pela dinamicidade destes espaços que se faz necessária a discussão acerca das dificuldades vivenciadas por estes grupos em relação à efetivação da regularização fundiária de seus territórios através de políticas públicas específicas.

Contudo, a alternativa proposta por esse trabalho se constitui na necessidade de reconhecimento das terras a serem regularizadas, no caso específico do Pará, a partir da implementação dos TEQs e efetivação do Programa Brasil Quilombola, a nível federal, para a garantia de outros direitos básicos que vão além do processo de regularização fundiária, levando em consideração as especificidades dos espaços periurbanos, em consonância com a possibilidade de acesso a crédito para o fomento de atividades rentáveis nesses locais.

\section{REFERÊNCIAS BIBLIOGRÁFICAS}

ALMEIDA, Alfredo Wagner Berno de. Quilombos e as Novas Etnias. In: ALMEIDA, Alfredo Wagner Berno de. Os Quilombos e as Novas Etnias. Manaus: UEA Edições. 2011. pp. 56-88. 
ANANINDEUA. Lei $\mathrm{n}^{\mathrm{o}} 2.380$, de 09 de julho de 2009. Institui as macrozonas urbanas no território municipal de Ananindeua e seu perímetro urbano. Disponível em: <www.seidurb.pa.gov.br>. Acesso em: 10 jan. 2016.

. Lei $n^{\circ} 2.237$, de 06 de outubro de 2006. Institui o Plano Diretor do Município de Ananindeua. Disponível em: <www.seidurb.pa.gov.br>. Acesso em: 10 jan. 2016.

ANJOS, Rafael Sanzio Araújo dos. Distribuição espacial das comunidades remanescentes de Quilombo no Brasil. Humanidades no 47. Brasilia: UNB. Novembro 1999. p. 87-98.

ARAÚJO, Renata Klautau Malcher de. As cidades da Amazônia do Século XVIII: Belém, Macapá e Mazagão. Porto: FAUP, 1998. p. 199 - 163.

BOYER, Véronique. A construção do objeto quilombo: da categoria colonial ao conceito antropológico. Disponível em: <file:///D:/Meus\%20Documentos/Downloads/Constru\%C3\%A7\%C3\% A3o\%20do\%20objeto $\% 20$ quilombo $\% 20-\% 20$ cate goria\%20colonial\%20ao\%20conceito\%20antropologico.pdf $>$. Acesso em: 07 jan. 2016.

BRASIL. Ato das Disposições Constitucionais Transitórias (1988). Ato das Disposições Constitucionais Transitórias. Disponível em: <www.planalto.gov.br>. Acesso em: 07 jan. 2016.

\section{Constituição (1988). Constituição da República Federativa do Brasil.}

Disponível em: <www.planalto.gov.br >. Acesso em: 07 jan. 2016.

. Decreto $\mathrm{n}^{\mathrm{o}}$. 4.887, de 20 de novembro de 2003. Regulamenta o procedimento para identificação, reconhecimento, delimitação, demarcação e titulação das terras ocupadas por remanescentes das comunidades dos quilombos de que trata o art. 68 do Ato das Disposições Constitucionais Transitórias. Disponível em: <www.planalto.gov.br>. Acesso em: 07 jan. 2016.

. Decreto-Lei n. 311, de 2 de março de 1938. Dispõe sobre a divisão territorial do país. Disponível em: <www.planalto.gov.br>. Acesso em: 28 dez. 2015.

. Lei $n^{\circ}$. 11.326, de 24 de julho de 2006. Estabelece as diretrizes para a formulação da Política Nacional da Agricultura Familiar e Empreendimentos Familiares Rurais. Disponível em: Disponível em: <www.planalto.gov.br>. Acesso em: 28 dez. 2015.

CONDURÚ, Marise Teles; PEREIRA, José Almir Rodrigues. Elaboração de trabalhos acadêmicos: normas, critérios e procedimentos. $4^{\circ}$ ed. rev. ampl. e atual. 2010.

CORRALO, Giovani da Silva. Município autonomia na federação brasileira. Curitiba: Juruá, 2006.

DAVIS, Mike. Planeta favela. São Paulo: Boitempo, 2006. p.15-77. 
DEZEN JUNIOR, Gabriel. Constituição Federal em esquemas. $3^{\text {a }}$ ed. Brasillia: Vestcon, 2012. p. 137-168.

DIAS, Daniella Maria dos Santos. O espaço na pós-modemidade: a necessária releitura do planejamento e do ordenamento territorial nos espaços urbanos e rurais. Rio de Janeiro: Lumen Juris, 2014.

ENDLICH, Ângela Maria. Perspectivas sobre o urbano e o rural. In: SPOSITO, Maria Encarnação Beltrão; WHITACKER, Arthur Magon (orgs.). Cidade e campo: relações e contradições entre rural e urbano. São Paulo: Expressão Popular, 2006. p. 11-32.

FISCHER, Luly Rodrigues da Cunha. Ordenamento territorial e planejamento municipal: estudo de caso das limitações supralocais à aplicação do art. 30, VIII da Constituição de 1988 pelo município de Parauapebas, Pará.Tese (Doutorado em Direito). Universidade Federal do Pará, Instituto de Ciências Jurídicas, 2014. p. 145-148

Regularização Fundiária de Áreas Patrimoniais Municipais no Pará e Produção Habitacional de Interesse Social: avanços e desafios. In: SANTANA, Joana Valente et al. A questão da habitação em municípios periurbanos na Amazônia. Belém: Edufpa. 2012. p. 371-386.

INCRA. Etapas da regularização quilombola. Brasilia: INCRA, 2016. Disponível em: <www.incra.gov.br>. Acesso em: 08 jan. 2016.

ITERPA. Instrução Normativa $n^{\circ}$. 03, de 09 de junho de 2010. Dispõe sobre as modalidades de assentamentos criadas pelo Iterpa. Disponível em: <www.iterpa.pa.gov.br>. Acesso em: 09 jan. 2016.

. Portaria $\mathrm{n}^{\mathrm{o}} 2.857$, de 16 de novembro de 2010. Cria o território estadual quilombola do Abacatal. Disponível em: <www.ioepa.com.br〉. Acesso em: 09 jan. 2016.

MARIN, Rosa Acevedo; CASTRO, Edna. No caminho de pedras de Abacatal: experiência social de grupos negros no Pará. Belém: NAEA/UFPA, $2^{\text {a }}$ ed. 2004.

MARIN, Rosa Acevedo; SABINO, Thiago Alan Guedes. Informativo Projeto Nova Cartografia Social da Amazônia no. 17: Quilombo de Abacatal, Ananindeua - PA: direitos territoriais e conflito socioambiental. Belém: Projeto Nova Cartografia Social, 2015.

MARQUES, Jane Aparecida; MALCHER, Maria Ataide Malcher (Org.). Cadernos Iterpa: territórios quilombolas. Vol. 3. Belém: ITERPA, 2009.

PARÁ. Constituição (1989). Constituição do estado do Pará. Disponível em: <www.senado.leg.br>. Acesso em: 07 jan. 2016.

Decreto $\mathrm{n}^{\circ} 713$, de 07 de dezembro de 2007. Dispõe sobre a criação dos Territórios

Estaduais Quilombolas. Disponível em: <www.ioepa.com.br>. Acesso em: 09 jan. 2016. 
Decreto $\mathrm{n}^{\circ}$. 2.690, de 28 de dezembro de 2010. Dispõe sobre a homologação do território estadual quilombola do Abacatal. Disponível em: <www.ioepa.com.br>. Acesso em: 07 jan. 2016.

Decreto $\mathrm{n}^{\mathbf{0}} 3.572$, de 22 de junho de 1999. Dispõe sobre territórios quilombolas. Disponível em: <www.ioepa.com.br>. Acesso em: 09 jan. 2016.

PRIOSTE, Fernando G. V., ALVES, Carolina C. N., CAMERINI, João Carlos B. Quem tem medo da Constituição Federal? Quilombos e o direito ao território. In SAUER, Sergio e ALMEIDA, Wellington (Org.) Terras e Territórios na Amazônia. Brasilia: Editora Universidade de Brasilia. 2011. pp. 297-316.

PROCURADORIA DE JUSTIÇA DE ANANINDEUA DO MINISTÉRIO PÚBLICO DO ESTADO DO PARÁ. Ananindeua: MPPA requer perícia técnica e encaminha solução no quilombo do Abacatal. Ananindeua: Ministério Público do Estado do Pará, 2015. Disponível em: <www.mppa.mp.br>. Acesso em: 10 jan. 2016.

ROCHA, Ibraim; TRECCANI, Girolamo Domenico; BENATTI, José Heder; HABER, Lilian Mendes; CHAVES, Rogério Arthur Friza. Manual de Direito Agrário Constitucional: lições de direito agroambiental. Belo Horizonte: Fórum, 2015. p.198-208

SALLES, Vicente. Os mocambeiros. Belém: IAP, 2013. p. 95-113.

SAQUET, Marcos Aurélio. Por uma abordagem territorial das relações urbano-rurais no Sudoeste paranaense. In: SPOSITO, Maria Encarnação Beltrão; WHITACKER, Arthur Magon (orgs.). Cidade e campo: relações e contradições entre urbano e rural. 3 ed. São Paulo: Outras Expressões, 2013.

SECRETARIA DE JUSTIÇA E DIREITOS HUMANOS DO ESTADO DO PARÁ. Secretário Michell Durans visita a comunidade do Abacatal, em Ananindeua, que passa por impactos ambientais. Disponível em: <www.sejudh.pa.gov.br.>.Acesso em: 09 jan. 2016.

TELES, Lehonna. O regime da titularidade das terras quilombolas em área urbana: 0 quilombo Sacopã. Disponível em: <http://www.pucrio.br/pibic/relatorio_resumo2010/relatorios/ccs/dir/DIR-Lehonna\%20Teles.pdf $>$. Acesso em: 29 dez. 2015.

TRECCANI, Girolamo Domenico. Terras de quilombo: caminhos e entraves da titulação. Belém: Secretaria Executiva de Justiça. Programa Raízes, 2006.

VALE, Ana Rute do; GERARDI, Lucia Helena de Oliveira. Crescimento urbano e teorias sobre o espaço periurbano: analisando o caso do município de Araraquara (SP). In: GERARDI, Lucia Helena de Oliveira; CARVALHO, Pompeu Figueiredo (orgs.). Geografia: ações e reflexões. 2006. $\quad$ p. 232-246. Disponível em: <http://www.rc.unesp.br/igce/geografia/pos/downloads/2006/crescimento_urbano.pdf $>$. Acesso em: 27 dez. 2015. 
VEIGA, José Eli da. Mudanças nas relações entre espaços rurais e urbanos. In: PIQUET, Rosélia; OLIVEIRA, Elzira de. Economia e território no Brasil contemporâneo. 2007. Disponível em: < http://www.zeeli.pro.br/wpcontent/uploads/2012/06/Mudancas_nas_relacoes_entre_espacos.pdf $>$. Acesso em: 13 jan. 2016.

Nem tudo é urbano. In: Ciência e cultura. Vol. 56. n. 2. São Paulo: 2004. Disponível em: <http://cienciaecultura.bvs.br/scielo.php?pid=S000967252004000200016\&script=sci_arttext $>$. Acesso em: 13 jan. 2016. 